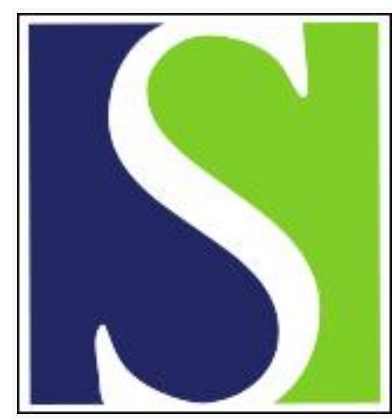

Scand J Work Environ Health 2004;30(5):362-370

https://doi.org/10.5271/sjweh.824

Issue date: Oct 2004

Central nervous system effects of acute organophosphate poisoning in a two-year follow-up

by Delgado E, McConnell R, Miranda J, Keifer M, Lundberg I, Partanen $T$, Wesseling $C$

Affiliation: Department of Preventive Medicine, Occupational Health Program, National Autonomous University of Nicaragua at León (UNAN-León), León, Nicaragua.

Refers to the following text of the Journal: 1998;24(1):18-29

Key terms: acute organophosphate poisoning; central nervous system; developing country; exposure; follow-up; intoxication; memory, verbal; pesticide; symptom; visuomotor function

This article in PubMed: www.ncbi.nlm.nih.gov/pubmed/15529800 


\title{
Central nervous system effects of acute organophosphate poisoning in a two-year follow-up
}

\author{
by Edgar Delgado, MD, ${ }^{1}$ Rob McConnell, MD, ${ }^{2}$ Jamilette Miranda, PhD, ${ }^{1,3}$ Matthew Keifer, MD, ${ }^{4}$ Ingvar \\ Lundberg, MD, , 5 Timo Partanen, PhD, ${ }^{6}$ Catharina Wesseling, PhD ${ }^{3,6}$
}

Delgado E, McConnell R, Miranda J, Keifer M, Lundberg I, Partanen T, Wesseling C. Central nervous system effects of acute organophosphate poisoning in a two-year follow-up. Scand $J$ Work Environ Health 2004;30(5):362-370.

Objectives Patients hospitalized for acute organophosphate poisoning in León, Nicaragua, were followed for effects on the central nervous system (CNS) over a 2-year period.

Methods Immediate verbal memory (Rey verbal learning), visuomotor performance (digit symbol), and neuropsychiatric symptoms (Q-16) were assessed for 53 poisoned persons at the time of hospital discharge, 7 weeks postpoisoning, and 2 years postpoisoning, and, at the same time intervals, for 28 persons who had never been poisoned. The poisonings were classified as moderate occupational (31), severe occupational (15), and severe through the oral route (7), representing low, medium, and high exposure, respectively. Longitudinal confounder-adjusted between-category comparisons and longitudinal analyses of variance and covariance were used to assess the effects of the exposure.

Results Immediate verbal learning showed deficits in the high-exposure group, in particular at the time of discharge, but the estimate of the difference when compared with the values of the unexposed was imprecise. Visuomotor performance showed a deficit at 7 weeks in the medium-exposure group, but it had improved after 2 years relative to that of the unexposed, for whom improvement had occurred at 7 weeks and persisted during the 2 years of follow-up, possibly a test-retest effect. Neuropsychiatric symptoms were in excess 2 years after the hospital discharge in the low- and medium-exposure groups and all the groups combined. All the results were imprecise for the small high-exposure group.

Conclusions Visuomotor performance and possibly short-term verbal memory seem to be affected early after severe acute organophosphate poisoning and recover, either truly or by some compensatory mechanism. Neuropsychiatric symptoms seem to increase after a longer latency period.

Key terms developing countries, exposure, follow-up, intoxication, pesticide, symptoms, verbal memory, visuomotor function.

Most pesticide poisonings, estimated at an annual 3 million cases worldwide, occur in developing countries, organophosphate insecticides being the most common cause (1). The rates of acute pesticide poisoning in Nicaragua have, for decades, been among the highest reported in the world (2). The Pan American Health Organization recently estimated that possibly 68000 intoxications occurred annually, most being occupational acute organophosphate poisonings (3).

Organophosphate insecticides inhibit the enzyme acetylcholinesterase, which controls the transmission of the nerve impulses at cholinergic synapses throughout the nervous system. The inhibition of the enzyme causes the accumulation of acetylcholine at the neurojunctions and

1 Department of Preventive Medicine, Occupational Health Program, National Autonomous University of Nicaragua at León (UNAN-León), León, Nicaragua.

2 Department of Preventive Medicine, University of Southern California, Los Angeles, California, United States.

3 Division of Occupational Health, Department of Public Health Sciences, Karolinska Institutet, Stockholm, Sweden.

4 International Scholars in Occupational and Environmental Health, University of Washington, Seattle, Washington, United States.

5 National Institute for Working Life, Stockholm, Sweden.

6 Central American Institute for Studies on Toxic Substances (IRET), Universidad Nacional, Heredia, Costa Rica.

Correspondence to: Dr Catharina Wesseling, Central American Institute for Studies on Toxic Substances (IRET-UNA), Universidad Nacional, PO Box 86-3000, Heredia, Costa Rica. [E-mail: cwesseli@una.ac.cr; ineke_wesseling@yahoo.com] 
result in symptoms of cholinergic overstimulation (4). The possibility of central nervous system (CNS) impairment persisting for several years after acute poisonings with organophosphate insecticides was first explored systematically in the 1960s (5), but the authors concluded that no significant difference was evident in physical examinations or neurological testing. Savage et al (6) examined the neurobehavioral performance of persons poisoned by acute organophosphate compounds an average of 9 years earlier. Inferior performances were observed on a wide range of neurobehavioral tests, with difficulties in memory, thinking, understanding, and problem solving and lowered scores on IQ (intelligence quotient) tests, as well as an excess of neuropsychiatric symptoms and a twofold elevation in the prevalence of neuropsychological deficits similar to brain damage. Additional epidemiologic studies among applicators and other workers with occupational poisonings in the United States, Costa Rica, Nicaragua, and South Africa have associated acute organophosphate intoxication with persistent impairment of a variety of neuropsychological functions (7-10) or with an excess of neurological symptoms (7-12).

Acute organophosphate poisonings may also affect the peripheral nervous system. Days after the acute onset of a poisoning, an "intermediate syndrome" may occur, characterized by paralysis of the proximal flexor and respiratory muscles (13), possibly related to pre- and postsynaptic dysfunction of neuromuscular transmission due to prolonged acetylcholinesterase inhibition (14). One to several weeks after the acute phase of a poisoning by "neuropathic" organophosphates, organophosphate-induced delayed polyneuropathy may appear, consisting of sensory and motor impairment due to the degeneration of large-diameter axons of the spinal cord and peripheral nerves (15). In Nicaragua, the neuropathic pesticides methamidophos and chlorpyrifos were identified as causes of these impairments (16-20). In addition to acute and chronic effects from poisonings, effects from long-term organophosphate exposures are less consistently but increasingly being reported. Studies in the United Kingdom and the United States found various types of dysfunction of the CNS $(12,21,22)$ and peripheral nervous system $(12,23,24)$ among workers with long-term organophosphate exposure or among those with combined recent and long-term exposures. No neurobehavioral (25) or sensory (10) deficits were found among farm workers in South Africa.

Evidence of associations between organophosphate exposure and chronic effects on the CNS is still insufficient, and more research has been encouraged on neurotoxicity in relation to organophosphate (26). All the epidemiologic studies carried out thus far have been cross-sectional. In our present study, a cohort of patients hospitalized for acute organophosphate poisoning was followed over a 2-year period, beginning with the intoxicating event. This cohort approach adds to previous knowledge from cross-sectional studies. It further tests the hypothesis of chronic CNS damage from overexposure to organophosphates that was high enough to result in clinical poisoning and, in addition, provides insight into the evolution of these changes and their resolution over time. The effects of acute organophosphate intoxication on the peripheral nervous system in this cohort have been described elsewhere (18-20).

\section{Study population and methods}

On three occasions, at the time of hospital discharge (examination I), at 7 weeks postpoisoning (examination II) and at 2 years postpoisoning (examination III), two neurobehavioral tests, the Rey verbal learning test (27) for immediate verbal memory and the digit symbol test for visuomotor speed (28), and a symptom questionnaire, Q-16 $(29,30)$, were administered to a group of persons poisoned by organophosphate pesticides and to a culturally and educationally comparable nonpoisoned group.

\section{Study population}

Between 1 July 1992 and 15 December 1996, all the persons hospitalized for acute organophosphate intoxication for at least 24 hours at either the University Teaching Hospital in León or the España Hospital in Chinandega, Nicaragua, were considered for recruitment. Seventy-seven men were enrolled. Six died during the acute phase, and one committed suicide before examination II. Six others were excluded from the study because they could be examined only once, and one person was excluded because of uncertainty as to the exact nature of the pesticide involved. One person refused to participate. The exposed population at examinations I and II thus consisted of 62 previously poisoned men. Of these, nine were lost to follow-up 2 years later. The poisoned population at examination III consisted of $53 \mathrm{men}$; $85 \%$ of the recruited poisoned men.

Initially, 74 men from fishing and cattle cooperatives located around León, Nicaragua, who had never been poisoned by pesticides, were randomly chosen for the nonpoisoned group. Thirty-five were later excluded because they participated only in examination I. Of these, 32 had moved out of the area, and 3 refused to continue to participate in the study. Thus the nonpoisoned group at examinations I and II consisted of 39 men (28 fishermen and 11 cattle farmers). Of these, 11 were lost to follow-up 2 years later, and the nonpoisoned group at examination III thus consisted of 28 workers (ie, $72 \%$ 
of the nonpoisoned group at the completion of recruitment). The general characteristics of the poisoned and nonpoisoned groups are shown in table 1 .

\section{Exposure}

Poisoning with an organophosphate insecticide was the exposure of concern, and the severity of the poisoning represented the levels of exposure. The workplaces and homes of about two-thirds of the poisoned men were visited to confirm whether the organophosphate pesticide annotated in the emergency room records caused the intoxication. The initial report of the causative agent was confirmed for all but three persons. In these cases, the pesticide was in an unlabeled bottle but was determined to be an organophosphate pesticide in a subsequent chemical analysis.

The severity of the intoxication was characterized by signs and symptoms. The severity classification was derived from the patterns of symptoms provided on a reporting form employed by the national surveillance system for pesticide poisonings. The form was routinely filled out by the physician attending the patient in the emergency room. Copies of the hospital chart and emergency room records were obtained for every poisoned person. An internist in our project (ED) classified the clinical severity of the poisonings. None of the hospitalized poisonings were classified as "mild". Poisonings classified as "moderate" involved weakness, dizziness, headache, or blurred vision, in combination with at least one of the following symptoms: vomiting, sialorrhea, fasciculations, abdominal pain, diarrhea, miosis, wheezing, or crepitus. For poisonings classified as "severe", the aforementioned symptoms and either diminished consciousness or cyanosis were listed in the clinical annotations. The hemoglobin-adjusted erythrocyte cholinesterase levels, determined with the Testmate acute organophosphate field kit (EQM Research, Cincinnati, OH, USA) (31) was studied for only a fraction of the poisonings. One patient was included among the severely poisoned because his acetylcholinesterase level was $2.6 \mathrm{IU} / \mathrm{g}$ of hemoglobin, almost four standard deviations below the mean of the nonpoisoned group [mean 28.0 (SD 6.6) IU/g of hemoglobin].

The severity of a poisoning with a certain toxicant is defined by the absorbed amount (internal dose), which is a function of the external dose and the route of absorption. Gastrointestinal absorption in oral organophosphate intake, accidentally or for suicidal purposes, is quicker than uptake through the skin, the main absorption route in occupational poisonings (32). Therefore, in poisonings with ingestion of the organophosphate, symptoms appear more rapidly and are usually more severe, especially in high-dose suicide attempts. Acute organophosphate poisonings due to attempted suicides and, to a less degree also poisonings due to accidental ingestion, have considerably higher fatality rates than occupational poisonings $(33,34)$. We therefore further classified the degree of exposure according to the circumstances of the poisonings. Data on the circumstances retrieved from the medical records yielded 46 occupational poisonings and 7 nonoccupational poisonings (six attempted suicides and one massive accidental ingestion). When the persons with missing data in the third examination were excluded from the analyses, the final exposure classification of the participants consisted of the following three levels of increasing severity: 31 moderate occupational poisonings (labeled "low-exposure group"), 15 severe occupational poisonings ("mediumexposure group"), and 7 severe nonoccupational poisonings through the oral route ("high-exposure group"). Table 2 shows the pertinent characteristics of the exposure.

\section{Confounders}

All of the participants were interviewed with a structured questionnaire for age, education, lifestyle, general health, and other previous neurotoxic exposures (see table 1). An alcohol consumption index was constructed by multiplying the amount of alcohol consumed by the reported frequency of consumption per month. In the poisoned group 10 subjects reported previous pesticide poisoning, whereas none in the nonpoisoned group had ever been poisoned by a pesticide. Previous work with

Table 1. Characteristics of the study population.

\begin{tabular}{|c|c|c|c|c|c|c|c|c|c|c|}
\hline \multirow[t]{2}{*}{ Group } & \multicolumn{2}{|c|}{$\begin{array}{c}\text { Age } \\
\text { (years) }\end{array}$} & \multicolumn{2}{|c|}{$\begin{array}{l}\text { Education } \\
\text { (years) }\end{array}$} & \multicolumn{4}{|c|}{$\begin{array}{l}\text { Occupation } \\
(\mathrm{N})\end{array}$} & $\begin{array}{l}\text { Alcohol } \\
\text { (g/month) }\end{array}$ & $\begin{array}{c}\text { Long-term or- } \\
\text { ganophosphate } \\
\text { exposure } \\
\text { (lifetime days) }\end{array}$ \\
\hline & Median & Range & Median & Range & $\begin{array}{c}\text { Cattle } \\
\text { farming }\end{array}$ & Fishing & $\begin{array}{l}\text { Agri- } \\
\text { culture }\end{array}$ & Other & Median Range & Median Range \\
\hline Nonpoisoned (N=28) & 25 & $15-47$ & 4 & $0-10$ & 1 & 27 & - & - & $358 \quad 0-3085$ & $0 \quad 0-480$ \\
\hline Poisoned (N=53) & 25 & $14-64$ & 4 & $0-11$ & - & - & 50 & 3 & $110 \quad 0-2465$ & $60 \quad 1-1032$ \\
\hline Moderate occupational ( $\mathrm{N}=31)$ & 23 & $15-64$ & 4 & $0-8$ & - & - & 29 & 2 & $127 \quad 0-1644$ & $601-1032$ \\
\hline Severe occupational $(\mathrm{N}=15)$ & 30 & $14-62$ & 4 & $0-11$ & - & - & 14 & 1 & $45 \quad 0-2465$ & $60 \quad 1-524$ \\
\hline Nonoccupational (oral route) $(\mathrm{N}=7)$ & 26 & $16-46$ & 2 & $0-6$ & - & - & 7 & - & $559 \quad 0-2426$ & $168 \quad 1-600$ \\
\hline
\end{tabular}


organophosphate insecticides was quantified with an organophosphate exposure index in total days of lifetime exposure (range 1-1032 days). No other potential confounders were reported by any of the participants, including exposures to other neurotoxic substances (solvents, arsenic, lead, mercury, and regular drug intake), loss of consciousness for over 30 minutes and diagnosed by a physician, occupational exposure to vibrating machinery, or history of chronic diseases (diabetes or thyroid, arthritis, kidney, or other neurological diseases).

\section{Testing}

Examination I was conducted at the time of the hospital discharge (between 1 to 31 days after the poisoning onset, median 6 days) using (i) the Rey auditory verbal learning test, (ii) the digit symbol test, and (iii) a modified Spanish version of the Q-16 to assess neuropsychiatric symptoms. Examination II was carried out between 24 to 180 days (median 48 days) after the poisoning. Examination III was carried out between 416 to 1251 days (median 838 days). The controls were also examined three times, at similar time intervals. All the participants were examined at the Oscar Danilo Rosales Argüello Hospital in León, Nicaragua. They all signed an informed consent approved by the ethics committee of the National Autonomous University of Nicaragua.

Rey auditory verbal learning is a test for immediate verbal memory function (27). The person recalls words from a standard 15-item list of ordinary objects (eg, hat, church, bell) read by the examiner. The procedure is repeated four times in a row. The fifth time the examiner reads a different list as a distracter. Then the examiner returns to reading the original list. The test score used was the number of items recalled by the subject after distraction. The same list of words was used on the three examinations. The digit symbol test is a subtask of the Wechsler Adult Intelligence Score and is also included in the WHO neurotoxicity chore test battery (28). It involves the learning of associations between numbers and symbols and perceptive motor velocity. The score is the number of symbols correctly drawn in 90 seconds. The modified Q-16 is a sum score of 16 symptoms concerning problems with memory and concentration, irritability and sadness, tiredness, palpitations, chest tightness, headaches, dizziness, numbness and tingling, difficulty buttoning clothing, loss of sensitivity, and sleeping problems. This originally Swedish test (29) was adapted and validated in Nicaragua (30). Each symptom was coded $0=$ no or $1=$ yes.

\section{Statistical analysis}

The data were analyzed with SPSS/PC for Windows v. 8.0 (SPSS Inc, Chicago, IL, USA). Only the 81 persons
Table 2. Exposure determinants and exposure categories. All poisoned participants $(\mathrm{N}=53)$.

\begin{tabular}{|c|c|c|}
\hline Category & $\mathrm{N}$ & $\%$ \\
\hline \multicolumn{3}{|l|}{ Exposure characteristics } \\
\hline \multicolumn{3}{|l|}{ Type of poisoning } \\
\hline Occupational & 46 & 86.8 \\
\hline Accidental & 1 & 1.9 \\
\hline Suicide attempts & 6 & 11.3 \\
\hline \multicolumn{3}{|l|}{ Severity of poisoning } \\
\hline Moderate & 31 & 58.5 \\
\hline Severe & 22 & 41.5 \\
\hline \multicolumn{3}{|l|}{ Type of organophosphate } \\
\hline Methamidophos & 20 & 37.7 \\
\hline Chlorpyrifos & 17 & 32.1 \\
\hline Other & 16 & 30.2 \\
\hline Edifenphos & 6 & 11.3 \\
\hline Methyl parathion & 4 & 7.5 \\
\hline Terbufos & 3 & 5.7 \\
\hline Phorate & 1 & 3.8 \\
\hline Malathion & 1 & 1.9 \\
\hline Fenthion & 1 & 1.9 \\
\hline \multicolumn{3}{|l|}{ Exposure categories } \\
\hline Not poisoned & 28 & . \\
\hline $\begin{array}{l}\text { Moderate occupational poisoning } \\
\text { (low exposure) }\end{array}$ & 31 & . \\
\hline $\begin{array}{l}\text { Severe occupational poisoning } \\
\text { (medium exposure) }\end{array}$ & 15 & . \\
\hline $\begin{array}{l}\text { Severe nonoccupational poisoning } \\
\text { through oral route }{ }^{a} \text { (high exposure) }\end{array}$ & 7 & . \\
\hline
\end{tabular}

a 6 suicidal and 1 accidental ingestion.

with no missing data were included. Two-way (time and exposure) analyses of variance (without confounders) and of covariance (with adjustment for age, education, and alcohol consumption) for repeated measures were done over the three times of testing, separately for exposure contrasts unexposed-all exposed, unexposedlow exposed, unexposed-medium exposed, and unexposed-high exposed. Interaction with time was tested with two degrees of freedom. Linear regression analyses were used to contrast the means of the endpoint changes in time ( 7 weeks versus discharge, 2 years versus discharge, and 2 years versus 7 weeks) between the aforementioned pairwise exposure contrasts, adjusted for age, education, and alcohol consumption. The number of symptoms, age, education, and alcohol consumption were log-transformed because of the positively asymmetric distributions.

\section{Results}

Tables 3-5 show the mean scores for the endpoint variables by group and time, and the results of the analyses of variance and covariance between the unexposed and one exposure group at a time. For the latter, P-values are shown for the main effects of exposure and the interaction effects between time and exposure. The mean 
Table 3. Unadjusted means and standard deviations of the Rey verbal learning test (immediate verbal memory) by exposure status, with P-values from the two-way analyses of variance (unadjusted) and the analyses of covariance (adjusted for age, education and alcohol consumption), and the adjusted mean differences in the changes and their $95 \%$ confidence intervals ( $95 \% \mathrm{Cl}$ ), contrasting each exposed group with the unexposed group.

\begin{tabular}{|c|c|c|c|c|c|c|c|c|c|c|c|c|c|c|}
\hline & \multicolumn{2}{|c|}{$\begin{array}{l}\text { Unexposed } \\
(\mathrm{N}=28)\end{array}$} & \multicolumn{3}{|c|}{$\begin{array}{c}\text { All exposed } \\
(\mathrm{N}=53)\end{array}$} & \multicolumn{3}{|c|}{$\begin{array}{l}\text { Low exposed } \\
\quad(\mathrm{N}=31)\end{array}$} & \multicolumn{3}{|c|}{$\begin{array}{l}\text { Medium exposed } \\
\qquad(\mathrm{N}=15)\end{array}$} & \multicolumn{3}{|c|}{$\begin{array}{l}\text { High exposed } \\
\qquad(\mathrm{N}=7)\end{array}$} \\
\hline & Mean & SD & Mean & SD & $95 \% \mathrm{Cl}$ & Mean & SD & $95 \% \mathrm{Cl}$ & Mean & SD & $95 \% \mathrm{Cl}$ & Mean & SD & $95 \% \mathrm{Cl}$ \\
\hline At discharge & 8.07 & 2.31 & 7.13 & 2.66 & . & 7.42 & 2.69 & . & 6.93 & 2.79 & . & 6.29 & 2.36 & . \\
\hline 7 weeks' follow-up & 7.96 & 2.30 & 7.15 & 2.27 & . & 7.16 & 2.05 & . & 7.13 & 2.53 & . & 7.14 & 2.91 & . \\
\hline 2 years' follow-up & 8.04 & 3.14 & 7.79 & 2.75 & . & 8.29 & 2.91 & . & 7.27 & 2.15 & . & 6.71 & 2.98 & . \\
\hline \multicolumn{15}{|c|}{ P-value for the main effect (exposure) } \\
\hline \multicolumn{2}{|l|}{$\begin{array}{l}\text { Unadjusted } \\
\text { Adjusted }\end{array}$} & . & \multicolumn{3}{|c|}{$\begin{array}{l}0.16 \\
0.18\end{array}$} & \multicolumn{3}{|c|}{$\begin{array}{l}0.45 \\
0.44\end{array}$} & \multicolumn{3}{|c|}{0.17} & \multicolumn{3}{|c|}{0.15} \\
\hline \multicolumn{15}{|c|}{ P-value for the interaction between time and exposure } \\
\hline \multicolumn{2}{|l|}{$\begin{array}{l}\text { Unadjusted } \\
\text { Adjusted }\end{array}$} & . & \multicolumn{3}{|c|}{$\begin{array}{l}0.55 \\
0.52\end{array}$} & $\begin{array}{l}0 . \\
0 .\end{array}$ & $\begin{array}{l}38 \\
33\end{array}$ & & $\begin{array}{l}0 . \\
0 .\end{array}$ & $\begin{array}{l}90 \\
95\end{array}$ & & $\begin{array}{l}0 . \\
0 .\end{array}$ & $\begin{array}{l}66 \\
45\end{array}$ & \\
\hline \multicolumn{15}{|c|}{ Adjusted difference in change against unexposed } \\
\hline $\begin{array}{l}7 \text { weeks versus discharge } \\
2 \text { years versus discharge } \\
2 \text { years versus } 7 \text { weeks }\end{array}$ & $\dot{.}$ & $\dot{.}$ & $\begin{array}{l}0.12 \\
0.73 \\
0.61\end{array}$ & $\begin{array}{l}\cdot- \\
\cdot- \\
\cdot-\end{array}$ & $\begin{array}{l}1.09-1.33 \\
0.57-2.03 \\
0.74-1.97\end{array}$ & $\begin{array}{r}-0.12 \\
1.00 \\
1.12\end{array}$ & $\begin{array}{l}\cdot . \\
\cdot . \\
\cdot\end{array}$ & $\begin{array}{l}-1.43-1.19 \\
-0.56-2.55 \\
-0.42-2.65\end{array}$ & $\begin{array}{r}0.26 \\
0.20 \\
-0.07\end{array}$ & $\dot{.}$ & $\begin{array}{l}-1.40-1.93 \\
-1.61-2.01 \\
-1.83-1.70\end{array}$ & $\begin{array}{r}1.32 \\
0.92 \\
-0.40\end{array}$ & $\dot{ }$ & $\begin{array}{l}-0.81-3.45 \\
-1.52-3.36 \\
-3.01-2.20\end{array}$ \\
\hline
\end{tabular}

Table 4. Unadjusted means and standard deviations of the digit symbol test (visuomotor performance) by exposure status, with Pvalues from the two-way analyses of variance (unadjusted) and the analyses of covariance (adjusted for age, education, and alcohol consumption), and the adjusted mean differences of the changes and their $95 \%$ confidence intervals ( $95 \% \mathrm{Cl}$ ), contrasting each exposed group with the unexposed group.

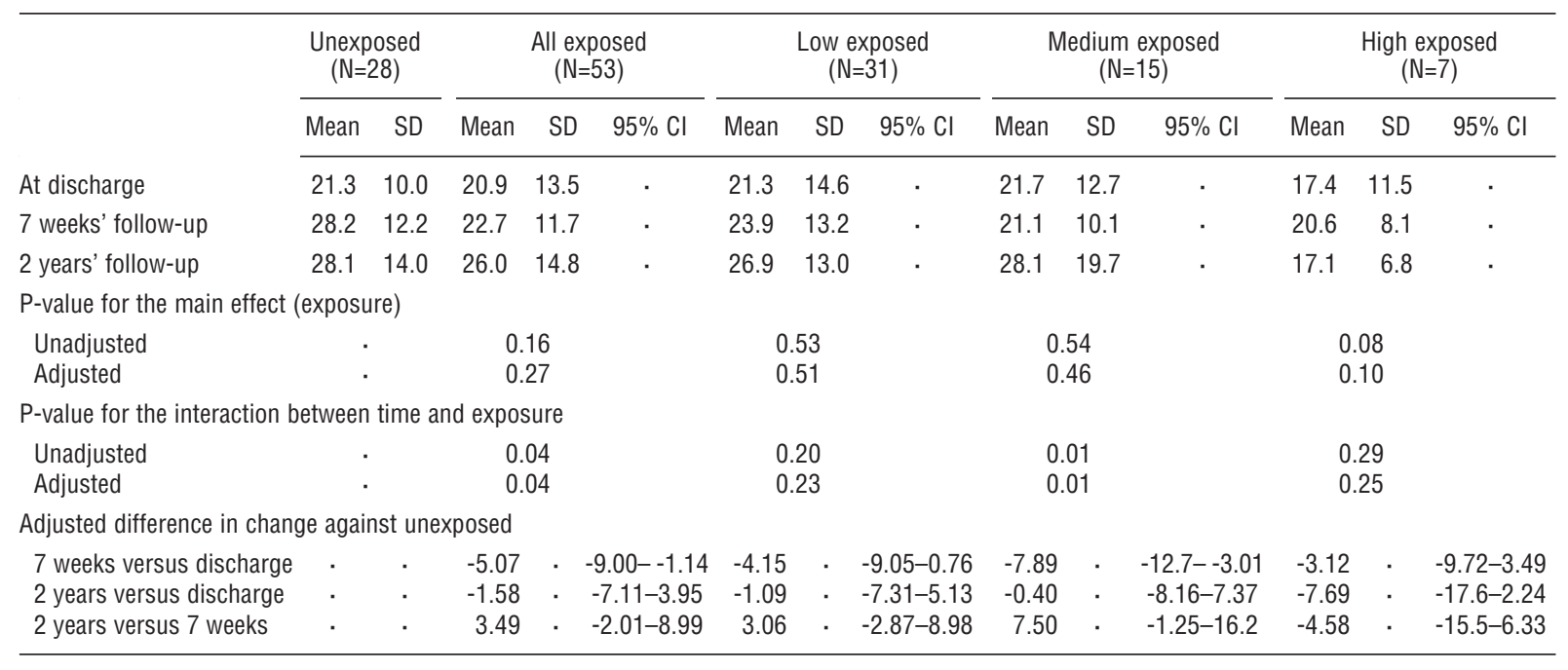

changes between each exposure group and the unexposed group at 7 weeks and 2 years are presented, adjusted for age, education, and alcohol consumption.

The Rey verbal learning score appeared to be little affected by exposure (table 3 ). The confidence intervals of the adjusted differences in the changes between the exposed and unexposed included the null value, and the P-values for the main effects of the exposure and the interactions between time and exposure were relatively high. The deficit at discharge in the high-exposure group was -1.7 (95\% CI -3.7-0.3) after adjustment for age, education, and alcohol consumption in a comparison with the unexposed group.
A deficit emerged in the adjusted digit symbol visuomotor performance 7 weeks after the poisoning in the medium-exposure group when compared with the unexposed group, the difference in the mean changes being -7.9 units (95\% CI -12.7--3.0) (table 4). This deficit had disappeared after 2 years. In the high-exposure group, visuomotor performance was depressed throughout the time of observation, particularly after 2 years, but the estimates lacked precision.

The adjusted Q-16 neuropsychiatric symptom score, for which the means are given on a $\ln$ (number of symptoms +1 ) metric, increased over the 2 years in all the groups, including a smaller change among the unexposed 
Table 5. Unadjusted means and standard deviations of the log of the Q-16 neuropsychiatric symptom score by exposure status, with Pvalues from the two-way analyses of variance (unadjusted) and analyses of covariance (adjusted for age, education, and alcohol consumption), and the adjusted mean differences of the changes and their $95 \%$ confidence intervals (95\% Cl), contrasting each exposed group with the unexposed group.

\begin{tabular}{|c|c|c|c|c|c|c|c|c|c|c|c|c|c|c|}
\hline & \multicolumn{2}{|c|}{$\begin{array}{l}\text { Unexposed } \\
\qquad(\mathrm{N}=28)\end{array}$} & \multicolumn{3}{|c|}{$\begin{array}{l}\text { All exposed } \\
(\mathrm{N}=53)\end{array}$} & \multicolumn{3}{|c|}{$\begin{array}{l}\text { Low exposed } \\
\qquad(\mathrm{N}=31)\end{array}$} & \multicolumn{3}{|c|}{$\begin{array}{l}\text { Medium exposed } \\
\qquad(\mathrm{N}=15)\end{array}$} & \multicolumn{3}{|c|}{$\begin{array}{l}\text { High exposed } \\
\qquad(\mathrm{N}=7)\end{array}$} \\
\hline & Mean & SD & Mean & SD & $95 \% \mathrm{Cl}$ & Mean & SD & $95 \% \mathrm{Cl}$ & Mean & SD & $95 \% \mathrm{Cl}$ & Mean & SD & $95 \% \mathrm{Cl}$ \\
\hline At discharge & 1.72 & 0.60 & 1.58 & 0.90 & 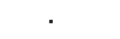 & 1.52 & 0.96 & . & 1.58 & 0.74 & . & 1.83 & 0.97 & . \\
\hline 7 weeks' follow-up & 1.72 & 0.49 & 1.46 & 0.97 & . & 1.43 & 0.97 & . & 1.27 & 1.03 & . & 2.03 & 0.70 & . \\
\hline 2 years' follow-up & 1.84 & 0.68 & 2.19 & 0.73 & . & 2.10 & 0.78 & . & 2.38 & 0.62 & . & 2.15 & 0.76 & . \\
\hline \multicolumn{15}{|c|}{ P-value for the main effect (exposure) } \\
\hline $\begin{array}{l}\text { Unadjusted } \\
\text { Adjusted }\end{array}$ & & \multicolumn{2}{|c|}{$\begin{array}{l}0.90 \\
0.85\end{array}$} & & \multicolumn{2}{|c|}{$\begin{array}{l}0.65 \\
0.60\end{array}$} & & \multicolumn{2}{|c|}{$\begin{array}{l}0.92 \\
0.99\end{array}$} & & \multicolumn{2}{|c|}{0.25} & \\
\hline \multicolumn{15}{|c|}{ P-value for the interaction between time and exposure } \\
\hline $\begin{array}{l}\text { Unadjusted } \\
\text { Adjusted }\end{array}$ & \multicolumn{2}{|l|}{. } & \multicolumn{2}{|c|}{$\begin{array}{l}0.007 \\
0.008\end{array}$} & & \multicolumn{2}{|c|}{$\begin{array}{l}0.020 \\
0.025\end{array}$} & & \multicolumn{2}{|c|}{$\begin{array}{l}0.001 \\
0.002\end{array}$} & & \multicolumn{2}{|c|}{$\begin{array}{l}0.80 \\
0.93\end{array}$} & \\
\hline \multicolumn{15}{|c|}{ Adjusted difference in change against unexposed } \\
\hline $\begin{array}{l}7 \text { weeks versus discharge } \\
2 \text { years versus discharge } \\
2 \text { years versus } 7 \text { weeks }\end{array}$ & $\dot{.}$ & $\dot{.}$ & $\begin{array}{r}-0.12 \\
0.48 \\
0.60\end{array}$ & $\begin{array}{l}\cdot \\
\cdot \\
\cdot\end{array}$ & $\begin{array}{l}0.51-0.26 \\
0.09-0.87 \\
0.22-0.99\end{array}$ & $\begin{array}{r}-0.10 \\
0.45 \\
0.55\end{array}$ & $\begin{array}{l}\cdot \\
\cdot \\
\cdot\end{array}$ & $\begin{array}{l}-0.51-0.31 \\
0.04-0.86 \\
0.13-0.96\end{array}$ & $\begin{array}{r}-0.30 \\
0.66 \\
0.96\end{array}$ & $\dot{.}$ & $\begin{array}{l}-0.75-0.15 \\
0.09-1.22 \\
0.46-1.45\end{array}$ & $\begin{array}{r}0.13 \\
0.12 \\
-0.01\end{array}$ & $\dot{.}$ & $\begin{array}{l}-0.46-0.71 \\
-0.66-0.89 \\
-0.49-0.47\end{array}$ \\
\hline
\end{tabular}

persons (table 5). The greatest increase in the number of symptoms was observed in the medium-exposure group, increasing, upon exponentiation, from 3.9 to 10.8 symptoms from hospital discharge to 2 years. Contrasting the changes among the exposed with those among the unexposed and adjusting for confounders, we found that the $95 \%$ confidence intervals of the effect estimates excluded the null value and the P-values for the exposure-time interaction were low, except in the high-exposure group.

\section{Discussion}

This is the first study to assess neurobehavioral performance and symptoms repeatedly in a group of persons acutely poisoned by organophosphate. The main findings were (i) impairment in the small high-exposure group in immediate verbal memory, in particular at the time of the hospital discharge, which remained statistically imprecise; (ii) a visuomotor deficit 7 weeks after poisoning in the medium-exposure group, which then disappeared; and (iii) a 2-year delayed excess of neuropsychiatric symptoms in the low- and medium-exposure groups.

We compared our findings 2 years after acute organophosphate poisoning with the results of previous studies that used similar tests to determine chronic effects (table 6). As in our study, two cross-sectional studies that used the Rey verbal learning test between 1 and 3 years after acute organophosphate poisoning did not find considerable memory impairment $(7,9)$. It seems that memory functions related to immediate verbal learning may be affected at the time of the poisoning, if at all, and recover quickly. In all the studies listed in table 6 , impaired memory was detected with tests other than the Rey test and thus may have measured, at least in part, different memory components than the Rey.

Weak performance of persons acutely poisoned by organophosphate on the digit symbol test has been consistently reported (table 6). We observed an impairment in all of our exposed groups 7 weeks after the hospital discharge, and the confounder-adjusted effect estimate excluded the null value for the pooled group of all the exposed men, and also for the medium-exposed group. A considerable improvement in the unexposed group was responsible for this deficit. This effect was likely to be a test-retest effect, which has been demonstrated elsewhere for the digit symbol test and for Wechsler performance IQ in general $(35,36)$.

Miranda et al (18) reported deficits in grip and pinch strength in this same cohort 7 weeks after acute organophosphate poisoning, most clearly among the persons with severe acute poisoning by organophosphates known to induce delayed polyneuropathy, with partial recovery 2 years after the acute organophosphate poisoning, except for the most severely poisoned person (20). Thus this similar pattern for effects on the peripheral nervous system may reflect that, in our cohort, the motor component of the digit symbol test was primarily responsible for the observed differences.

Excess symptoms were detected in all the studies listed in table 6. The previous Nicaraguan and Costa Rican studies found an excess prevalence of Q-16 symptoms among severe [ie, hospitalized (7)], and mild [ie, not hospitalized (9)] persons with acute poisoning from organophosphates between 1 and 3 years after the poisoning. 
Table 6. Comparison of seven studies with neurobehavioral tests or symptom questionnaires after poisoning with organophosphate pesticides. [ $\uparrow=$ better performance, $\downarrow=$ worse performance, $==$ similar performance, $\cdot \cdot=$ data not available (test not performed)]

\begin{tabular}{|c|c|c|c|c|c|c|c|c|c|c|c|}
\hline \multirow[t]{3}{*}{ Test } & \multicolumn{11}{|c|}{ Study } \\
\hline & \multicolumn{4}{|c|}{$\begin{array}{l}\text { Present study } \\
\qquad(N=53)^{a}\end{array}$} & \multirow{2}{*}{$\begin{array}{c}\begin{array}{c}\text { Savage } \\
\text { et al, } \\
1988(6) \\
(\mathrm{N}=100)^{\mathrm{b}}\end{array} \\
\begin{array}{c}\text { All kinds } \\
\text { (uninten- } \\
\text { tional) }\end{array}\end{array}$} & \multirow{2}{*}{$\begin{array}{c}\text { Rosenstock } \\
\text { et al, } \\
1991(7) \\
(\mathrm{N}=36)^{\mathrm{c}} \\
\text { Hospi- } \\
\text { talized } \\
\text { (occupa- } \\
\text { tional) }\end{array}$} & \multicolumn{2}{|c|}{$\begin{array}{c}\text { Steenland } \\
\text { et al, } \\
1994(8) \\
(\mathrm{N}=128)^{d}\end{array}$} & \multirow{2}{*}{$\begin{array}{c}\text { Wesseling } \\
\text { et al, } \\
2002(9) \\
(\mathrm{N}=53)^{\mathrm{c}} \\
\begin{array}{c}\text { Nonhos- } \\
\text { pitalized } \\
\text { mild (occu- } \\
\text { pational) }\end{array}\end{array}$} & \multirow{2}{*}{$\begin{array}{c}\begin{array}{c}\text { Steenland } \\
\text { et al, }\end{array} \\
\begin{array}{c}2000(12) \\
(\mathrm{N}=8)^{\mathrm{e}}\end{array} \\
\begin{array}{c}\text { Self- } \\
\text { reported }\end{array}\end{array}$} & \multirow{2}{*}{$\begin{array}{c}\begin{array}{c}\text { Stallone } 8 \\
\text { Beseler, } \\
2002(11) \\
(\mathrm{N}=69)^{\dagger}\end{array} \\
\begin{array}{c}\text { Self- } \\
\text { reported }\end{array}\end{array}$} \\
\hline & $\begin{array}{c}\text { All } \\
\text { hospital }\end{array}$ & $\begin{array}{c}\text { Low } \\
\text { expo- } \\
\text { sure } \\
(\mathrm{N}=31)\end{array}$ & $\begin{array}{c}\text { Medium } \\
\text { expo- } \\
\text { sure } \\
(\mathrm{N}=15)\end{array}$ & $\begin{array}{c}\text { High } \\
\text { expo- } \\
\text { sure } \\
(\mathrm{N}=7)\end{array}$ & & & $\begin{array}{l}\text { All kinds } \\
\text { (uninten- } \\
\text { tional) }\end{array}$ & $\begin{array}{c}\text { Trend } \\
\text { days } \\
\text { off } \\
\text { work) }\end{array}$ & & & \\
\hline Rey verbal learning & $=$ & $=$ & $=$ & $\downarrow$ & .. & $\downarrow$ & .. & .. & $\uparrow$ & .. & .. \\
\hline Other memory tests & .. & .. & .. & .. & $\downarrow g$ & $\downarrow g$ & $\uparrow$ & $\downarrow g$ & $\downarrow$ & $=$ & .. \\
\hline Digit symbol & $=$ & $=$ & $=$ & $\downarrow g$ & $\downarrow g$ & $\downarrow g$ & $\downarrow$ & $\downarrow g$ & $\downarrow$ & $=$ &.. \\
\hline$Q-16$ or modified $Q-16$ & $\downarrow g$ & $\downarrow$ & $\downarrow g$ & $\downarrow$ &.. & $\downarrow g$ & .. & .. & $\downarrow g$ & $\downarrow g$ & $\downarrow g$ \\
\hline Other symptom questionnaires & s.. & .. & .. & .. & $\downarrow g$ & $=$ & $\downarrow g$ & $\downarrow$ & $\downarrow g$ & .. & .. \\
\hline
\end{tabular}

a Time between poisoning and examination 2 years.

${ }^{\mathrm{b}}$ Time between poisoning and examination an average of 9 years.

c Time between poisoning and examination 1-3 years.

${ }^{d}$ Time between poisoning and examination an average of 8 years.

e Time between poisoning and examination not specified.

${ }^{\mathrm{f}}$ Time between poisoning and examination during lifetime.

${ }_{9} \mathrm{P}<0.05$.

In the United States, two studies using other symptom questionnaires for persons poisoned up to 11 years earlier $(6,8)$ and two recent studies using a modified version of the Q-16 reported symptom excesses after the poisoning $(11,12)$. The symptoms reported in these studies include increased memory and concentration problems, anger, irritability, tension, fatigue, depression, paranoia, defensiveness, confusion, and social withdrawal, as well as headaches, heart palpitations, numbness and tingling, and loss of muscle strength. London et al (10) also found an association between chronic neurological symptoms and previous acute occupational poisoning with organophosphates among South African farm workers in a study primarily examining the effects from long-term organophosphate exposure.

Symptom reporting is often viewed as a less objective and inferior outcome parameter than objective function tests. However, when chronic CNS effects from acute organophosphate poisonings are evaluated, it seems to be a highly consistent effect (table 6). It has been pointed out that symptoms, although highly person$\mathrm{al}$, are nonetheless real and they may correlate well with objective measurements, be early indicators of disease, or be inherent aspects of the disease itself (37). Noteworthy in the context of research on toxic chronic nervous system damage is that an exposure-response association has been shown for cumulative organic solvent exposure and neuropsychiatric symptoms, possibly as an expression of chronic affective syndrome, without consistent evidence from objective psychometric tests results (38).

Primary depression in the highest exposure group (ie, severe poisonings through oral intake) with six of the seven persons having attempted suicide, may be the cause for increased symptoms, as well as for the worse test performance, although the evidence for effects remained weak because of the low statistical power. A psychiatric evaluation of these patients during their hospital stay indicated that they had all ingested pesticide on impulse and that none of them actually suffered depression. This group, contrary to the occupational poisonings, more frequently reported irritability and sadness than the unexposed had at the time of the hospital discharge, but not at examinations II and III (data not shown).

The fact that symptom excess was not found in our cohort early after occupational poisoning but was clearly high 2 years after the event may point towards subtle permanent CNS damage. Primary depression is an unlikely explanation for the excess symptom prevalence in the occupationally poisoned subgroups at the end of the follow-up. One possibility is that symptoms are a late manifestation of slowly progressive CNS damage. An alternative explanation is that mood alterations reflect difficulties of poisoned persons to cope with diminished capacities in several important brain functions, such as memory, attention, and motor and sensory abilities, or difficulties with higher mental agility functions, which our testing would not have detected. The symptoms that increased most on the Q-16 were those related to the peripheral nervous system, the prevalences among the poisoned being approximately three times higher at examination III than at examination II (loss of sensitivity in extremities $43 \%$ versus $15 \%$, numbness and tingling sensations $57 \%$ versus $17 \%$, and difficulty buttoning $23 \%$ versus $8 \%$ ). This finding is in accordance with the results of the clinical examinations of this same cohort, since the clinical examinations detected an increase in symptoms and signs related to sensory 
function in all the poisoned persons at the end of the follow-up (20).

We do not have data on the premorbid intellectual capacity for our subjects, but large differences between the unexposed and exposed persons seem unlikely. It was confirmed during the fieldwork that the groups were very similar in socioeconomic status, and many fishermen also practiced small-scale agriculture. However, the high-exposure group (severe poisoning through oral intake) had received fewer years of education, and the less amount of education may partly explain the persisting lower performance with respect to the verbal memory and visuomotor functions of this group. Years of education was adjusted for in the analyses.

We evaluated the effect of the loss of participants over time by comparing the performance of the persons who were still in the study at examination II versus those we had lost. The six occupational and three nonoccupational (oral route) dropouts did worse at examination II on each of the three tests, as compared with the other poisoned persons in the corresponding exposure category who remained in the study. These differences were not negligible, especially for the oral-route dropouts on the digit symbol test $(\mathrm{P}=0.06)$. Potential bias was in the direction of an underestimation of the effect. Conversely, the dropouts among the unexposed men $(\mathrm{N}=11)$ performed somewhat less well on the Rey verbal learning and digit symbol tests than the remaining unexposed men did, and, therefore, some bias occurred in the opposite direction for these latter tests.

It is possible that poisonings caused by organophosphate agents were included in the poisoned group since we could not check the agent in situ for about $35 \%$ of the poisonings. However, the symptoms and signs in the clinical examination support the probability that these pesticides were cholinesterase inhibitors. Furthermore, the poisonings for which the agent was confirmed were all due to acute organophosphates. Gross misclassification of exposure can therefore be excluded. The examinations were done blind to the exposure status, but it is likely that, for a considerable number of patients, the examiner may have inferred the exposure status. In addition, the period during which the testing was done covered 4 years, and practices in test administration may have varied over time. However, the evaluations of poisoned and nonpoisoned persons were well mixed during the entire study period, and adherence to the protocol was strict. In addition, testing of the nonpoisoned three times for reference would have diminished any effects of differences in the test administration. The variation in the period since poisoning was rather large within each of the three examinations. However, a multivariate model that included days since the poisoning event did not change the results for any of the three examinations (results not presented).
In conclusion, the available data suggest that visuomotor performance and possibly verbal memory are affected early after acute organophosphate poisoning but the effects disappear, either truly or by some compensatory mechanism. Visuomotor deficits may persist in severely poisoned persons. Neurological symptoms would appear later among persons with less severe occupational poisoning, but may stay permanently.

\section{Acknowledgments}

The authors thank the Department for Research Cooperation of the Swedish International Development Cooperation Agency (Sida/SAREC) for its financial support.

We are indebted to the epidemiology departments of the Hospital Escuela Oscar Danilo Rosales Arguello (HEODRA), León, and Hospital España, Chinandega, for giving us access to patient records.

\section{References}

1. World Health Organization (WHO) and United Nations Environmental Program (UNEP). Public health impact of pesticides used in agriculture. Geneva: WHO; 1990.

2. McConnell R. Occupational health in developing countries: pesticides in Nicaragua. In: Hogsted C, Reuterwall C, editors. Progress in occupational epidemiology. Amsterdam: Elsevier Science Publishers; 1988

3. Corriols M, Silva D, Marín J, Berroterán J, Lozano LM, Martínez J. Incidencia de intoxicaciones agudas por plaguicidas y estimación del subregistro en Nicaragua [Incidence of acute pesticide intoxications and underregistration estimates in Nicaragua]. Managua (Nicaragua\{?\}): Organización Panamericana de Salud/ Organización Mondial de Salud; 2002.

4. Gallo MA, Lawryk NJ. Organic phosphorus pesticides. In: Hayes W, Laws ER, editors. Handbook of pesticide toxicology, vol 2: classes of pesticides. San Diego (CA): Academic Press Inc; 1991. p 917-1123.

5. Tabershaw IR, Cooper C. Sequelae of acute organic phosphate poisoning. J Occup Med 1966;1:5-20.

6. Savage E, Keefe T, Heaton R, Lewis J, Burcar P. Chronic neurological sequelae of acute organophosphate pesticide poisoning. Arch Environ Health 1988;43:38-45.

7. Rosenstock L, Keifer M, Daniell W, McConnell R, Claypoole K. Chronic central nervous system effects of acute organophosphate pesticide intoxication. Lancet 1991; 338:223-7.

8. Steenland K, Jenkins B, Ames R, O’Malley M, Chrislip D, Russo J. Chronic neurological sequelae to organophosphate pesticide poisoning. Am J Public Health 1994;84:731-6.

9. Wesseling C, Keifer M, Ahlbom A, McConnell R, Moon JD, Rosenstock L, et al. Long-term neurobehavioral effects of mild poisoning with organophosphate and n-methyl carbamate pesticides among banana workers. Int J Occup Environ Health 2002;8:27-34. 
10. London L, Nell V, Thompson M-L, Myers JE. Effects of long-term organophosphate exposures on neurological symptoms, vibration sense and tremor among South African farm workers. Scand J Environ Health 1998;24:18-29.

11. Stallone L, Beseler C. Pesticide illness, farm practices, and neurological symptoms among farm residents in Colorado. Environ Res 2002;90:89-97.

12. Steenland K, Dick RB, Howell RJ, Chrislip DW, Hines CJ, Reid TM, et al. Neurologic function among termiticide applicators exposed to chlorpyrifos. Environ Health Perspect 2000;108:293-300.

13. Senanayake N, Karalliedde L. Neurotoxic effects of organophosphorus insecticides. An intermediate syndrome. N Eng J Med 1987;316:761-3.

14. De Bleecker J, Van Den Neucker K, Colardyn F. Intermediate syndrome in organophosphorus poisoning: a prospective study. Crit Care Med 1993;21:1706-11.

15. Lotti M. The pathogenesis of organophosphate polyneuropathy. Crit Rev Toxicol 1992;21:465-87.

16. McConnell R, Keifer M, Rosenstock L. Elevated quantitative vibrotactile threshold among workers previously poisoned with methamidophos and other organophosphate pesticides. Am J Ind Med 1994;25:325-34.

17. McConnell R, Delgado E, Cuadra R, Torres E, Keifer M, Almendárez J, et al. Organophosphate neuropathy due to methamidophos: biochemical and neurophysiological markers. Arch Toxicol 1999;73:296-300.

18. Miranda J, Lundberg I, McConnell R, Delgado E, Cuadra R, Keifer M, et al. Onset of grip- and pinch-strength impairment after acute poisonings with organophosphate insecticides. Int J Occup Environ Health 2002;8:19-26.

19. Miranda J, McConnell R, Delgado E, Cuadra R, Keifer M, Wesseling $\mathrm{C}$, et al. Tactile vibration thresholds after acute poisonings with organophosphate insecticides. Int J Occup Environ Health 2002;8:212-9.

20. Miranda J, McConnell R, Wesseling C, Cuadra R, Delgado E, Torres E, et al. Muscular strength and vibration thresholds during two years after acute poisoning with organophosphate insecticides. Occup Environ Med [journal on the Internet] 2004 [cited 2004 June 29];61:e4. Available from: http:// oem.bmjjournals.com/contents-by-date.0.shtml

21. Stephens R, Spurgeon A, Calvert I, Beach J, Levy L, Berry $\mathrm{H}$, et al. Neuropsychological effects of long-term exposure to organophosphate in sheep dip. Lancet 1995; 345:1135-9.

22. Fiedler N, Kipen H, Kelly-McNeil K, Fenske R. Long-term use of organophosphates and neuropsychological performance. Am J Ind Med 1997;32:487-96.

23. Stokes L, Stark A, Marshall E, Narang A. Neurotoxicity among pesticide applicators exposed to organophosphates. Occup Environ Med 1995;52:648-53.

24. Pilkington A, Buchanan D, Jamal GA, Gillham R, Hansen S, Kidd M, et al. An epidemiological study of the relations between exposure to organophosphate pesticides and indices of chronic peripheral neuropathy and neuropsychological abnormalities in sheep farmers and dippers. Occup Environ
Med 2001;58:702-10.

25. London L, Myers JE, Nell V, Taylor T, Thompson ML. An investigation into neurologic and neurobehavioral effects of long-term agrichemical use among deciduous fruit farm workers in the Western Cape, South Africa. Environ Res 1997;73:132-45.

26. Steenland K. Chronic neurological effects of organophosphate pesticides. BMJ 1996;312:1312-3.

27. Rey A. L'examen clinique en psychologie [Clinical psychological examination]. Paris: Presses Universitaires de France; 1964.

28. World Health Organization (WHO), Office of Occupational Health. Operational guide for the WHO neurobehavioral test battery. Geneva: WHO; 1986.

29. Hogstedt C, Andersson K, Hane M. A questionnaire approach to the monitoring of early disturbances in central nervous functions. In: Aitio R, Riihimäki K, Vainio H, editors. Biological monitoring and surveillance of workers exposed to chemicals. Washington (DC): Hemisphere Publishing Corporation; 1984.

30. Rodezno R, Lundberg I, Escalona E. Development of a questionnaire in Spanish on neurotoxic symptoms. Am J Ind Med 1995;28:505-20.

31. McConnell R, Cedillo L, Keifer M, Palomo MR. Monitoring organophosphate insecticide exposed workers for cholinesterase depression: new technology for office or field use. $\mathrm{J}$ Occup Med 1992;34:34-7.

32. Reigart J, Roberts J. Recognition and management of pesticide poisonings. 5th edition. Washington (DC): US Environmental Protection Agency (EPA); 1999. EPA-735-R-98-003 p 34-47.

33. Wesseling C, Castillo L, Elinder C-G. Pesticide poisonings in Costa Rica. Scand J Work Environ Health 1993;19:227-35.

34. Jeyaratnam J. Acute pesticide poisoning: a major global health problem. World Health Stat Q 1990;43:139-44.

35. Matarazzo JD, Carmody TP, Jacobs LD. Test-retest reliability and stability of the WAIS: a literature review with implications for clinical practice. J Clin Neuropsych 1980;2:89-105.

36. Kaufman AS. Practice effects. In: Sternberg RJ, editor. Encyclopedia of human intelligence, volume II. New York (NY): McMillan; 1994. p 828-33.

37. Wegman D. Investigations into the use of symptom reports for studying toxic epidemics. In: Rantanen J, Lehtinen S, Kalimo R, Nordman H, Vainio H, Viikari-Juntura E, editors. New epidemics in occupational health: proceedings of the International Symposium on New Epidemics in Occupational Health; 16-19 May, 1994; Helsinki. Helsinki: Finnish Institute of Occupational Health; 1994. People and Work Research reports 1, p 124-38.

38. Lundberg I, Michélsen H, Nise G, Hogstedt C, Högberg M, Alfredsson L, et al. Neuropsychiatric function of housepainters with previous long-term heavy exposure to organic solvents. Scand J Work Environ Health 1995;21 suppl 1:44 p.

Received for publication: 11 August 2003 